\title{
A DIDÁTICA COMO FORMA PROPULSORA NA EFETIVIDADE DA PRÁTICA DOCENTE
}

Thaila Fernanda Goveia ${ }^{1}$ Heiji Tanaka

GOVEIA, T. F.; TANAKA H. A didática como forma propulsora na efetividade da prática docente. EDUCERE - Revista da Educação, Umuarama v. 17, n. 2, p. 187-202, jul./dez. 2017.

RESUMO: O presente trabalho tem como objetivo relatar as práticas e os desafios encontrados no dia a dia do professor do Ensino Superior. O estudo e análise da didática, compreendendo a sua definição, utilização bem como contribuição para melhor prática voltada ao ensino superior. Nos dias atuais, o professor, precisa utilizar de diferentes métodos e critérios fundamentais para a transmissão do conhecimento de forma completa e com significado, com metodologia inovadora, mediadora, trabalhando a realidade vivenciada pelos alunos. O professor universitário transmite seus conhecimentos aos seus alunos da forma como aprendeu, mas para isso é necessário que o professor, compreenda o que é ensinar. E principalmente diferenciar do aprender, uma vez que o professor no mesmo momento que ensina também aprende. É fundamental que o docente tenha consciência de que é seu dever ensinar com excelência, transmitir suas aulas de forma prazerosa e significativa, não apenas de forma mecânica, mas utilizando de diferentes meios para enriquecer suas aulas e consequentemente os alunos construírem seus conhecimentos. O professor precisa ter um olhar diferenciado para a educação nos dias atuais, uma vez que a tecnologia é uma importante ferramenta educacional e que precisa somar com o professor por se tratar da importância que os meios de tecnologia têm para os jovens, por deixá-los conectados com o mundo num simples toque.

PALAVRAS-CHAVE: Didática; Metodologia; Professor.

DOI: $10.25110 /$ educere.v17i2.2017.6596

${ }^{1}$ Formada em Pedagogia pela Universidade Paranaense - Unipar. Especialista em Docência e Gestão do Ensino Superior. Professora de Educação Infantil na rede municipal de Umuarama. Avenida Duque de Caxias, 5706. E-mail: thailagoveia@hotmail.com.

${ }^{2}$ Professor da Universidade Paranaense - Unipar. E-mail: htanaka@prof.unipar.br 


\section{DIDACTICS AS A PROPELLING FORM IN THE EFFECTIVENESS OF TEACHING PRACTICE}

ABSTRACT: This paper has the purpose of reporting the practices and challenges found in the daily activities of Higher Education professors. It studies and analyzes didactics, understanding its definition and use as well as its contribution toward better practices focusing on higher education. Currently, professors need to use different methods and criteria in order to transfer knowledge to students in a complete and meaning manner, using an innovative methodology, that of mediator, working the reality experienced by them. The university professor conveys his knowledge to his students as he learned it, but in order to do that, the professor must understand what teaching means, and especially be able to differentiate it from learning, since the professor, at the same time is teaching something but also learning from the realities. It is essential for the professor to be aware that he is bound to teach with excellence, transferring his knowledge in a pleasant and meaningful way, rather than mechanically, but also using different means to enrich his classes and consequently aid the students in building their knowledge. The professor needs to take a different look at education nowadays, since technology plays an important educational role and must be added to the professor's tools, since it is of pivotal importance for young people, making them connected to the world by the touch of a button.

KEYWORDS: Didactics; Methodology; Professor.

\section{LA DIDÁTICA COMO FORMA PROPULSORA EN LA EFECTIVIDAD DE LA PRÁCTICA DOCENTE}

RESUMEN: El presente trabajo tiene como objetivo relatar las prácticas y los desafíos encontrados en el día a día del profesor de Enseñanza Superior. El estudio y análisis de la didáctica, comprendiendo su definición, utilización, así como contribución para una mejor práctica orientada a la enseñanza superior. En los días actuales, el profesor, necesita utilizar de diferentes métodos y criterios fundamentales para la transmisión del conocimiento de forma completa y con significado, con metodología innovadora, mediadora, trabajando la realidad vivenciada por los alumnos. 
El profesor universitario transmite sus conocimientos a sus alumnos de la forma en que aprendió, pero para ello es necesario que el profesor entienda lo que es enseñar. Y principalmente diferenciar del aprendizaje, una vez que el profesor en el mismo momento que enseña también aprende. Es fundamental que el docente tenga conciencia de que es su deber enseñar con excelencia, transmitir sus clases de forma placentera y significativa, no sólo de forma mecánica, sino utilizando de diferentes medios para enriquecer sus clases y consecuentemente los alumnos construir sus conocimientos. El profesor necesita tener una mirada diferenciada para la educación en los días actuales, ya que la tecnología es una importante herramienta educativa y que necesita sumar con el profesor, por tratarse de la importancia que los medios de tecnología tienen para los jóvenes, por dejarlos conectados con el mundo en un simple toque.

PALABRAS CLAVE: Didáctica; Metodología; Profesor.

\section{INTRODUÇÃO}

A Didática como forma propulsora na efetividade da prática docente, busca relatar a importância de se adotar diferentes métodos e critérios de ensino, abordando o ensino e a educação prestados para os alunos.

Segundo Consolaro (2002) a didática está representada na arte de ensinar, onde o ensinar existe desde muitos tempos atrás, necessariamente desde os tempos dos gregos que transmitiam o que sabiam a quem precisasse, sem distinção. Exercendo dessa forma seu papel social.

Analisar o papel do professor universitário, nos dias atuais, requer muita atenção, pois ele precisa sempre estar renovando seus conhecimentos, com cursos e formações adequados, adquirindo novos métodos e formas de transmitir o conhecimento de forma significativa de fácil compreensão. Visando sempre ao processo de interação do aluno com o que se ensina. O professor utilizando de sua didática deve ter consciência do que se ensina, como ensina e principalmente para que ensina.

O caminho para a mudança desse paradigma se dá através da educação. O professor tem em suas mãos os conteúdos reflexivos e provocantes que buscam instruir os alunos a pensarem em como se deve agir e viver para a aquisição do conhecimento, sendo a busca necessária para as mudanças dos métodos e das realidades existentes.

A arte de transmitir o conhecimento não deve ser vista como um 
dom divino, já que para uma boa atuação é necessário tempos de estudos e aperfeiçoamento, ter a compreensão de que é fundamental estar em constante busca pelo conhecimento com novos métodos de ensino e tecnologias que a cada dia se modificam e transformam a forma de ver e pensar na prática.

"Quem ensina aprende ao ensinar e quem aprende ensina ao aprender" (FREIRE, 1996, p. 23). Diante disso, vemos como se dá e como deve ser a prática e a didática utilizada pelo professor. O professor em sua prática precisa estar preparado para os debates e trocas de experiências e conceitos que acontecerão no decorrer de suas aulas, proporcionando desse modo a proximidade entre docente e discente, somando para o aprendizado de coisas novas. É através da didática, da interação entre professor e aluno e dos diferentes métodos adotados, que a mediação, a construção do conhecimento e do processo de ensino com significado acontecem. Ficando sobre a responsabilidade do professor a sua didática de ensino, transformando-a em ponte para uma nova perspectiva de ensino significativo, mediando os conteúdos a serem explorados.

\section{DEFINIÇÃO DE DIDÁTICA}

Entende-se por didática por meio da interpretação de teoria de diferentes autores como um conjunto de métodos, normas e princípios teóricos que buscam em suma a alfabetização ou assimilação do conteúdo proposto e, consequentemente, o conhecimento, dos quais a escola tem o dever de transmitir por meio de diferentes técnicas e meios criteriosos. A didática dessa forma é fundamental para a educação nos dias atuais. As inovações da tecnologia, dos meios de informações e meios de transmissão dos conhecimentos fizeram com que as didáticas se aperfeiçoassem, garantindo ensino com qualidade (GASPARIN, 2010).

Com a evolução da didática, surgiu a necessidade de maior preparo entre professores, sendo que os conhecimentos e os novos métodos de ensino transformam se em um meio de construir o conhecimento tornando-o significativo.

O professor em sala de aula não transmite apenas o conteúdo planejado, mas toda segurança e carinho, transformando desse modo o espaço da sala de aula num mundo de construção e descoberta mediante 
a didática por ele adotada, dos métodos de ensino que permitem maior envolvimento com o aluno, capaz de gerar a transformação não apenas na sala de aula, mas na vida desse aluno, transmitindo a satisfação para a família e sociedade em geral, (GASPARIN, 2010).

O desenvolvimento humano está estritamente ligado as suas interações com os outros, com o meio e como estas estão organizadas. Esta análise evidencia a necessidade de movimentos de transformações das escolas, das didáticas aplicadas, do trabalho adequado e significativo do professor (LIBÂNEO, 1994).

Sabe-se que o caminho para a transformação das escolas será longo, porém extremamente necessário, além de apoio legal, recursos materiais e especializados esse movimento necessita de recursos humanos, pessoas capacitadas e, acima de tudo interessadas em contribuir para a efetivação desse processo. Dentre esses estão os professores que, acima de tudo, necessitam estar preparados para as mudanças nos métodos de ensino, buscando sempre o aprendizado do aluno em sua totalidade, os novos meios de ensino que evoluiem dia após dia. Para que o aluno esteja inteirado com o novo jeito de ensinar e aprender.

Segundo Libâneo (1994), é função primordial do professor:

Assegurar aos alunos o domínio mais seguro e duradouro possível dos conhecimentos científicos; Criar as condições e os meios para que os alunos desenvolvam capacidades e habilidades intelectuais de modo que dominem métodos de estudo e de trabalho intelectual visando a sua autonomia no processo de aprendizagem e independência de pensamento;

Orientar as tarefas de ensino para objetivo educativo de formação da personalidade, isto é, ajudar os alunos a escolherem um caminho na vida, a terem atitudes e convicções que norteiem suas opções diante dos problemas e situações da vida real (LIBÂNEO, 1994, p. 71).

O professor precisa sempre ter o olhar diferenciado para as necessidades de aprendizagem dos alunos; precisa ser inovador, planejar de forma diferente as aulas, nas quais os alunos possam se interessar pelos conteúdos. As aulas, mesmo que na parte teórica, precisam ser ricas de ensinamentos e exemplos para que o aprendizado seja significativo. $\mathrm{O}$ 
professor precisa ser o mediador dos conteúdos, fazendo perguntas, não apenas repassar os conteúdos prontos, com respostas formadas.

Segundo Cavalcanti (2002), o professor precisa ser um agente transformador juntamente com seus alunos, mediando as informações, permitindo que os alunos se sintam inquietos para a busca de novos conceitos e aprendizados. A troca de experiências e vivências garante de forma satisfatória a qualidade do ensino nas diferentes disciplinas em que atuam.

Se o professor é um mediador do processo de aprendizagem para a formação do aluno a qualidade desta "mediação interfere nos processos intelectuais, afetivos e sociais do aluno, o mesmo tem tarefas importantes a cumprir". (CAVALCANTI, 2002, p.20)

A formação adquirida no período da faculdade deixa uma lacuna de aperfeiçoamento se o professor não der continuidade aos cursos necessários para especialização e ampliação do conhecimento. Ainda em Cavalcanti (2002) o professor de ensino superior precisa estar em constante aperfeiçoamento, aprofundando os conhecimentos de forma contínua, sempre em busca de formação teórica e prática para que possa contribuir de forma positiva no ensino aos alunos, garantindo desse modo a formação (CAVALCANTI, 2002, p.21).

Diante destes pontos indagam-se os seguintes tópicos: Que didática é essa? Onde ela está?

Não existe prática pedagógica sem a contribuição e utilização da didática. $\mathrm{O}$ professor em sala de aula precisa, a todo o momento, utilizar a didática para transmitir o conhecimento aos seus alunos, garantindo desse modo o processo de ensino e aprendizagem.

Candau (2005) apresenta a dimensão e a importância da didática em sala de aula, uma vez a sua utilização permite maior interação e o processo de ensino e aprendizagem torna-se significativo, sendo que:

- A dimensão humana ocorre por meio de aquisições de atitudes como forma de um crescimento pessoal que envolve como principais componentes a afetividade, o calor, bem como a empatia.

- A dimensão técnica analisa o processo perante quais condições propiciará uma melhor aprendizagem, condições por melhores conteúdos, estratégias de ensino onde todo tempo 
se questiona: “O que fazer"? Para quê? Como?

- A dimensão político-social é toda a prática pedagógica voltada a pensar "Que formação"? Que organização social? Segundo Vasconcelos (2003, p. 47)

Ser professor "implica participar da formação do caráter, da personalidade, da consciência, da cidadania do educando [...] tendo como mediação os conhecimentos historicamente elaborados e relevantes".(VASCONCELOS, 2003, p 47).

O que se percebe é que as realidades dos estudos necessitam de trabalhos com professores que busque inovar suas aulas, abordando diferentes conteúdos, que chamem a atenção dos alunos, envolvendo-os em processos metodológicos, evitando, dessa forma, o comportamento inadequado que venha a atrapalhar a aula e o aprendizado.

\section{ENSINO SUPERIOR}

No Brasil, o Ensino Superior deu-se início por volta de 1808, com a chegada da família real, o que antes não existia. A educação chegou junto com a necessidade de se ter o ensino profissionalizante, formando o primeiro colégio médico cirúrgico, o que permitiu o crescimento do Ensino Superior e as mudanças que até nos dias atuais se fazem necessário para a adequação e aperfeiçoamento dos cursos profissionalizantes. (CUNHA, 1980)

Segundo Cunha (1980) no Brasil o Ensino Superior foi constituído apenas para atender uma pequena elite, filhos de pessoas importantes que aqui residiam, com o intuito de ensinar e formar cidadãos. As mudanças com o Ensino Médio começaram a ocorrer a partir da Proclamação da Independência e duram até os dias atuais na busca de formação adequada e o ensino de qualidade.

O que antes era o ensino voltado apenas para as questões políticas, passou a ser introduzidas universidades, oferecendo ensino profissionalizante para a sociedade, promovendo medidas de acesso ao ensino para todos sem distinção, de acordo com as possibilidades de cada estudante. (MARTINS, 2002).

Dentro deste novo cenário o Ensino Superior é o que possui mais 
desafios no processo de ensino, em que a importância do ensinar com qualidade está passando a ser irrelevante, ignorando os esforços dos professores e alunos surgindo a inserção de ensinos denominados "massificadores", que nada mais é a irrelevância do ensino com qualidade para a ampliação do número de pessoas possuidoras de diplomas. Formando desse modo profissionais despreparados com qualidade de ensino "aquém" ao objetivo esperado. (ZABALA, 1998).

O professor do Ensino Superior tem o papel fundamental de transmitir os conhecimentos necessários para a formação acadêmica. Isso só será possível por meio da prática docente preparada para atuar em salas de aulas, com conteúdos inovadores, com diferentes métodos e ferramentas na busca do ensino de qualidade. A formação do professor se faz necessária para que ele atue neste nível de ensino. A formação adequada com capacitação constante se torna fundamental para a atuação no Ensino Superior. O professor para atuar nas salas de aula do Ensino Superior necessita de formação em licenciatura, bacharel ou tecnólogo na área de conhecimento no qual deseja atuar (MIZUKAMI, 2001).

\section{RELAÇÃO ENTRE O PROFESSOR E O ALUNO, BEM COMO FAZER A RELAÇÃO COM O PAPEL DO PROFESSOR NA ATU- ALIDADE}

A formação dos professores precisa ser fundamentada e significativa, obtendo formação adequada, condição de trabalho digno, tendo consequentemente vontade em ensinar e mais ainda em fazer diferença na vida desses alunos que vivem cercados de tecnologias e que, muitas vezes, apresentam a desmotivação em aprender sendo essa por diferentes motivos. (TIBA, 2002).

Para que a educação aconteça e ofereça qualidade com respeito à diversidade dos educandos, é necessário que se invista na formação dos educadores do Ensino Superior, pois estes recebem todos os dias indivíduos que já possuem uma idealização de pensamento permitindo desse modo debates sobre o que é certo ou errado, sobre o modo de viver e de ver o mundo. (ZABALA, 1998).

Ainda em Zabala, (1998) podemos afirmar que:

As atividades de ensino devem promover aprendizagens mais 
significativas e funcionais possíveis, que tenham sentido e desencadeiem uma atitude favorável para realizá-las, que permitam o maior número de relações entre os distintos conteúdos, que constituam estruturas de conhecimento, por um lado. Por outro, devem facilitar a compreensão de uma realidade que nunca se apresenta compartimentada (ZABALA, 1998, p.186).

Como já foi mencionado, o professor é o responsável por possibilitar um ambiente adequado e rico em conhecimento, permitindo desse modo maior interação entre aluno e professor e, principalmente compreensão dos conteúdos, capazes de gerar a transformação não apenas na sala de aula, mas na vida desses indivíduos. Tornando-se um agente modificador para uma sociedade mais justa e conscientizada.

Sabe-se que o caminho de transformação das escolas será longo, porém extremamente necessário. Além de apoio legal, recursos materiais e especializados esse movimento demanda de recursos humanos, pessoas capacitadas e, acima de tudo, interessadas em contribuir para a efetivação desse processo.

Segundo Candau (2000, p.89):

O educador nunca estará definitivamente "pronto", formado, pois que sua preparação, sua maturação se faz no dia a dia, na mediação teórica sobre sua prática. A sua constante atualização se fará pela reflexão diurna sobre os dados de sua prática. Os âmbitos do conhecimento que lhe servem de base não deverão ser facetada, estanque e isolada de tratamento do seu objeto de ação: a educação. Mas serão, sim, formas de ver e compreender globalmente, na totalidade, o seu objeto de ação. (CANDAU, 2000, p 89).

O mundo contemporâneo exige uma formação continuada dos profissionais da educação, objetivando torná-los conscientes das diferenças existentes, visando sempre, promover estratégias, métodos e tecnologias capazes de promover a integração de todos sem distinção ou exclusão, o que representa a reprovação na missão de educar.

O que se vê nos dias atuais são indagações que insistem em fazer parte do cotidiano do educador como: Como ensinar, como transmitir conhecimentos? Quais métodos e critérios utilizar para que o aluno aprenda 
o conteúdo proposto?

Para educar seus alunos, o professor precisa desenvolver um repertório de intervenções, diferentes temas e conteúdos de diversidades culturais, debate que envolva todos os alunos, ou a maioria deles, temas que lhe interessem. Desse modo, o professor conseguirá ministrar suas aulas de forma adequada. (FREIRE, 2006)

As diferentes formas de ensino existentes nos dias atuais fazem com que o uso da criatividade ganhe destaque nos métodos de ensino. As vivências e crenças passadas deram lugar às diferentes ferramentas de ensino atuais, com diferentes métodos de ensino, permitindo ao professor um ensino de qualidade e alunos aprendendo com significado de forma concreta, o que permite ao professor avaliar o aluno durante todo o processo de ensino aprendizagem, de mediação e construção. Com utilização da criatividade e critérios que desenvolva o conhecimento (TIBA, 2006).

Sabe-se que quando os conteúdos são organizados e anteriormente preparados, a tranquilidade e segurança permeiam a sala de aula, trazendo segurança às ações diárias do professor e modificação nos conceitos de aprendizagem dos alunos para com o professor, garantindo dessa forma um ensino com qualidade e significado.

\section{DIDÁTICAS E A TECNOLOGIA - INOVAÇÃO OU OPOSIÇÃO AO ENSINO SUPERIOR}

Falar em comunicação, tecnologia e informação nos dias atuais, é colocar em debate questões que levantam a análise para uma nova maneira de transmitir os conteúdos e informações de forma direta, acessível e abrangente, sem censura ou proibições. Com novas tecnologias, democratizando e dando direito de expressão a todos (LUCKESI, 2004)

A mídia e os meios de comunicação, com novas tecnologias disponíveis a todos e em todos os lugares, permitem que o mundo se desenvolva cada vez mais e em ritmo acelerado. A sociedade em geral e, principalmente, a educação são os maiores sofredores de interferências do modo de se viver e pensar. (MORAES, 2010).

A referência de valores e modos de ser e pensar tem a ver com o fato de que são no domínio da comunicação que se esculpem os contornos da ordem hegemônica, seus tentáculos ideoló- 
gicos, suas hierarquias, suas expansões contínuas no bojo da mercantilização generalizada dos bens simbólicos (MORAES, 2010, p. 94).

Esta realidade tão acessível, ao mesmo tempo em que possui um papel fundamental para o desenvolvimento da tecnologia, muitas vezes prejudica a forma de ensinar dos professores. A luta desse professor pela atenção e colaboração dos alunos torna cada vez mais explícita nas salas de aulas, principalmente nas salas de aulas dos alunos que cursam o Ensino Superior (VALENTE, 1993).

O professor precisa estar apto para saber lidar com o aluno que não quer participar, que tem em mãos uma ferramenta que na maioria das vezes entrega o conteúdo pronto, sem ao menos ler ou pesquisar sobre o tema proposto. Estão presos em suas telas impedidos de pesquisar de buscar o conhecimento pela comodidade de ter o mundo ao toque de uma tela (SILVA, 1997).

A realidade da educação, nos dias atuais, nos possibilita fazer uma reflexão sobre os métodos que utilizamos para que haja o ensino aprendizagem de maneira eficaz com significado.

A evolução da tecnologia a cada dia vem crescendo de forma que só tem a somar com o processo de ensino e aprendizagem se for usada de forma a contribuir por meio da pesquisa científica, auxiliando assim para a construção do significado do conhecimento do aluno. (VALENTE, 1993).

Refletir sobre a educação em nossa realidade é fazer uma revisão histórica da sua trajetória na escola. Afinal, enquanto instituição, essa constitui um espaço em que se destina, além de todo o processo de ensino-aprendizagem, também a construção da cidadania, inserir este aluno diante de uma sociedade que evolui a cada dia, prepará-lo para buscar respostas as suas indagações e não ficar preso aos métodos de "copiar e colar", de se ter tudo pronto, que impedem o mesmo de explorar novos conteúdos.

E o computador e os diferentes meios de tecnologias existentes devem estar para este aluno como uma importante e segura ferramenta de estudo que lhe permitirá explorar o mundo, tendo como critério o buscar, pesquisar, realizar novos métodos de leitura e interpretação.

A pesquisa científica deve estar para a educação para o trabalho 
com o aluno de maneira que ele venha investigar, buscar respostas, analisar, ler, resumir para então obter o resultado de seus estudos. Não se deve permitir que a nova geração que está em nossas mãos para aprender, tenha em mente a ideia de ter tudo pronto, de apenas copiar e colar de retirar as informações prontas, sempre com o intuito de tirar vantagens. Os profissionais como: professores, educadores, formadores de cidadãos aptos para preparar profissionais tem a obrigação de mostrar a direção, de ensinar com diferentes métodos de ensino, mas com o mesmo intuito, de aprender.

É ele que, de maneira responsável, deve escolher por sua trajetória, ficando na responsabilidade do professor ser um medidor, que viabilizará um espaço de reflexão e questionamento, como um conselheiro e amigo capaz de discutir algumas dúvidas.

O professor deve ser a ponte para esta construção. Segundo Feuerstein (1983) apud Meier (2009) um professor mediador deverá fazer perguntas que acentuem o processo de aprendizagem e não o seu produto.

As escolas atuais têm crescido no estudo e no desenvolvimento de uma metodologia de concepção interacionista, pela qual são valorizadas as ações individuais, os trabalhos em equipe, o desenvolvimento de projetos que envolvam a construção do conhecimento inter e transdisciplinar. Nesse contexto, o professor necessita transformar sua postura "cognitivista" para adotar uma postura de mediador da aprendizagem, tanto quanto necessita mediar às relações entre os sujeitos de aprendizagem quanto aos seus conflitos, emoções, resistências, preferências e repulsas. (FEURSTEIN, 1980 apud MEIER, 2009).

Porém, ela só estará contribuindo para essa conquista se, ao promover a educação propiciar, sobretudo, condições que possibilitem aos indivíduos se tornarem conscientes de seu direito a reivindicar o mesmo acesso (SOARES, 2010, p.56).

Com métodos de ensino voltados para a pesquisa e na elaboração de novas construções de conhecimentos, o professor proporciona diferentes formas de atividades cerebrais, fazendo com que o aluno pense, analise, instigue perguntas pertinentes ao conteúdo proposto, sendo dessa forma a pesquisa uma ferramenta fundamental para a construção do conhecimento.

A principal preocupação é com a educação e como ela está sendo 
repassada aos alunos, sendo a propulsora para a formação de uma sociedade menos excludente, dotados de conhecimento, construtora do futuro por meio de seu esforço e enriquecimento cultural, contribuindo para melhor educação do país.

A educação deve ter como principal prioridade a formação de profissionais, garantindo o direito e a dignidade de todos.

\section{CONSIDERAÇÕES FINAIS}

Nos dias atuais além de todos os avanços da tecnologia, a educação também vem sofrendo muita modificação exige-se muitas inovações, novas formas de ensino, métodos criteriosos que buscam sempre a aprendizagem dos alunos visando ao ensino significativo.

A transformação acontece na prática pedagógica, na postura dos professores e alunos, buscando desse modo o processo de mediação para melhor desenvolvimento cognitivo e social do aluno sem distinção.

Os conteúdos ao sofrerem as transformações exigidas, modificam não apenas a forma de pensar sobre o assunto, mas principalmente na forma de ensinar.

Não se passa mais apenas conteúdos no quadro, onde os alunos de forma mecanizada copiam os conteúdos. A nova educação começa a instigar o aluno, o professor engloba conteúdos de forma completa, permitindo a mediação, a busca pelos resultados e significados, a construção do conhecimento de forma ampla e aprofundada, tornando mais significativo o aprendizado que o mesmo irá levar por toda a vida.

O professor passa ser o transmissor e colaborador para que o conhecimento aconteça não mais de maneira obrigatória, mas sim de forma prazerosa e significativa. As transformações educacionais envolvem bem mais que equipe pedagógica comprometida, alunos, disciplinas ou cursos ofertados, mas sim toda uma sociedade que se beneficia de maior conhecimento e, principalmente, maior desenvolvimento, cognitivo e social.

"Formar é muito mais que puramente treinar o educando (FREIRE, 2002 p. 15)" O que se percebe é que as realidades dos estudos necessitam de trabalhos com professores que busquem não apenas conteúdos prontos, mas a grande importância é que os alunos estejam envolvidos em processos metodológicos, nos quais professores e alunos realizem es- 
tudos significativos com resultados que mostrem a realidade social, em temas que abrange a realidade das necessidades e situações que mereçam destaques, ficando na responsabilidade do professor ser um mediador, que viabilizará um espaço de reflexão e questionamento.

Outro critério importante para a elaboração desses temas em estudos é que as aulas precisam ser completas, mediadas por professor e preparados para trabalhar os conteúdos propostos, em que os alunos tenham métodos e critérios argumentais para a realização dos trabalhos propostos garantindo dessa forma maior desenvolvimento cognitivo.

\section{REFERÊNCIAS}

CANDAU, V. M. Reinventar a escola. Petrópolis, RJ: Vozes, 2000 a.

CANDAU, M. V. A didática em questão. Petrópolis. Editoras Vozes. 25ed. 2005.

CAVALCANTI, L.S. Geografia e prática de ensino. Goiânia: Alternativa, 2002.

CONSOLARO, A. O "Ser" Professor: Arte e Ciência de Ensinar e Aprender. Maringá: Dental Pres. 3ed. 2002.

\section{CUNHA, L.A.A Universidade Temporã - o ensino superior da}

Colônia à Era de Vargas. Rio de Janeiro, Civilização Brasileira, 1980.

Diretrizes Curriculares Nacionais do curdo de graduação em Administração. Disponível em: http://portal.mec.gov.br/cne/arquivos/ pdf/ces-0134.pdf. Acesso em: 15 out. 2016.

Diretrizes Curriculares Nacionais para o curso de Pedagogia. Disponível em: http://portal.mec.gov.br/cne/arquivos/pdf/pcp05_05.pdf. Acesso em: 15 out. 2016.

Ensino Superior no Brasil: da descoberta aos dias atuais. Disponível em: http://www.scielo.br/pdf/\%0d/acb/v17s3/15255.pdf. Acesso em: 15 out. 2016. 
FREIRE, P. Pedagogia da autonomia: saberes necessários a prática educativa. São Paulo: Paz e Terra, 1996.

FREIRE, P. Pedagogia da autonomia: saberes necessários à prática educativa. São Paulo: Paz e Terra, 2006.

FREIRE, P. Pedagogia do Oprimido. 24a ed. Rio de Janeiro: Paz e Terra, 1997.

GASPARIN, J. L.; N., M.T.F.; TERUYA, T. K.

(Org.). Didática: processos de trabalho em sala de aula. 2. Ed. rev. e ampl. Maringá: EDUEM, 2010. (Formação de Professores - EaD, n. 14).

LIBÂNEO, J. C. Didática. São Paulo: Cortez, 1994.

LUCKESI, C. C. O papel da didática na formação do educador. In: CANDAU, Vera Maria (org.). A didática em questão. 23 $3^{\mathrm{a}}$ ed. Petrópolis, RJ: Vozes, 2004.

MARTINS, A. M. Autonomia da escola: a (ex) tensão do tema nas políticas públicas. São Paulo: Cortez, 2002.

MEIER, M. - GARCIA, S. Mediação da Aprendizagem: contribuições de Feuerstein e de Vygotsky, $5^{\mathrm{a}}$ edição, editora Grafiven, Curitiba - Pr, 2009.

MIZUKAMI, M.G. N. Ensino: as abordagens do processo. São Paulo: EPU, 2001.

MORAES, D. de. Gramsci e as mutações do visível. In: Moraes, Dênis. Mutações do visível: da comunicação de massa à comunicação em rede / Dênis de Moraes (organizador). Rio de Janeiro: Pão e Rosas, 2010.

SILVA, M. G. P. Da. O computador na perspectiva do desenvolvimento profissional do professor. Campinas, SP: FEA, 1997. 
SOARES, M. B.. Letramento: um tema em três gêneros. $4^{\text {a }}$ edição. Belo Horizonte: Autêntica, 2010 a. [1ª versão é de 1998].

TIBA, I. Quem ama educa. São Paulo: Gente, 2002.

TIBA, I. Ensinar aprendendo: novos paradigmas na educação. 18. Ed. rev. e atual. São Paulo: Integrare, 2006.

VALENTE, J.A. (1993a). Diferentes Usos do Computador na Educação. In J.A. Valente (Org.), Computadores e Conhecimento: repensando a educação (p.1-23). Campinas, SP: Gráfica da UNICAMP.

VASCONCELOS, C.S. Para onde vai o professor? Resgate do professor como sujeito de transformação. $10^{\mathrm{a}}$ ed. São Paulo: Libertad, 2003.

ZABALA, A. Enfoque globalizador e pensamento complexo: uma proposta para o currículo escolar. Porto Alegre: Artmed, 1998.

Recebido em: 27/04/2017 Aprovado em: 14/07/2017 